\title{
Verification of effects on the nervous system of low level occupational exposure to $\mathrm{CS}_{2}$
}

\author{
Marc W M M Ruijten, Herman J A Sallé, Maarten M Verberk
}

\begin{abstract}
Neurotoxic effects associated with long term low level occupational exposure to $\mathrm{CS}_{2}$ were reinvestigated four years after the initial study in the same group of workers. The second study concerned 44 exposed and 31 matched control workers. For both studies a personal cumulative exposure $E_{c}$ was calculated based on function specific exposure levels and the occupational histories, which were carefully re-established. The exposed workers' average $E_{c}$ was 192 and 213 ppm-years (first and second study respectively). Where possible the values of both data sets were used in a final combined analysis. Effects were found on the motor nerve conduction velocity of the fast $(-0.9 \mathrm{~m} / \mathrm{s})$ and slow $(-1.0 \mathrm{~m} / \mathrm{s})$ fibres of the peroneal nerve, the sensory nerve conduction velocity in the hand and arm segment of the median $(-2.1 \mathrm{~m} / \mathrm{s})$ and ulnar $(-1.3 \mathrm{~m} / \mathrm{s})$ nerves, and in the sural nerve $(-1.3 \mathrm{~m} / \mathrm{s})$. An increased refractory period was found in the sural nerve $(+0.2 \mathrm{~ms},+11 \%)$, but not in the peroneal nerve. For the autonomic nervous system an effect was found on the heart frequency response to isometric muscle contraction $(-4.7$ beats/min, $-26 \%)$ and maximal forced respiration $(-3.2$ beats $/ \mathrm{min},-16 \%)$. This study shows the importance of a detailed evaluation of past exposure data. The reinvestigation enabled a more precise estimation of the effects of $\mathrm{CS}_{2}$, which is particularly desirable at around threshold exposure.
\end{abstract}

\section{(British fournal of Industrial Medicine 1993;50:301-307)}

It is well known that occupational exposure to carbon disulphide $\left(\mathrm{CS}_{2}\right)$ may result in peripheral neuropathy of the central-peripheral distal axonal type. Subclinical nerve impairment has been found after

Coronel Laboratory, University of Amsterdam, Faculty of Medicine, AMC, Meibergdreef 15, 1105 AZ Amsterdam

M W M M Ruijten, H J A Sallé, M M Verberk exposure to only $8 \mathrm{ppm} \cdot{ }^{1-7}$ In a previous study in viscose rayon workers we were able to show small effects on the nervous system that were partly related to a lifetime cumulative exposure; the exposure to $\mathrm{CS}_{2}$ had mostly been low (1-17 ppm during an average of 20 years) and, unlike the findings of other studies, constant during the preceding 35 years. ${ }^{1}$ A tentative estimation was made of the neurotoxic no effect level for 40 years of exposure.

The objective of this study was to verify the effects found in the first study by (1) careful analysis of each worker's exposure history as well as the category specific exposure levels; (2) relating revised exposure to the original clinical state; (3) use of more extensive and precise neurophysiological tests; and (4) comparison of past results with present ones. Finally, we aimed to quantify the effect of $\mathrm{CS}_{2}$ from both studies.

\section{Methods}

SUBJECTS

All 87 participants of the first study were invited for the second study; 80 workers participated, two refused, one had died, and four were absent in the study period. In the first study the controls had been matched on a group basis for age, shift work, and nationality. The same three exposed and two control workers as in the first study were excluded

Table 1 Original and revised exposure categories with their respective $\mathrm{CS}_{2}$ concentrations. The estimation of the concentrations was based on 174 and 326 personal air samples respectively. The exposure in the other factory ended 14 years before the second study. The exposure of the three transporters ended six years before the second study.

\begin{tabular}{|c|c|c|c|}
\hline \multicolumn{2}{|l|}{ Original } & \multicolumn{2}{|l|}{ Revised } \\
\hline Function & conc (ppm) & conc (ppm) & Function \\
\hline Shift supervisor & 1 & $\begin{array}{l}1 \\
7\end{array}$ & $\begin{array}{l}\text { The same } \\
\text { spinner }\end{array}$ \\
\hline Spinner & & 24 & transporter \\
\hline Bleacher, high & 17 & $\begin{array}{r}20 \\
14\end{array}$ & $\begin{array}{l}\text { The same } \\
\text { batch compiler }\end{array}$ \\
\hline Bleacher, mediun & $12<$ & & batch handler \\
\hline $\begin{array}{l}\text { Bleacher, low } \\
\text { Other factory }\end{array}$ & $\stackrel{8}{20-30}$ & $\stackrel{8}{20-30}$ & $\begin{array}{l}\text { The same } \\
\text { The same }\end{array}$ \\
\hline
\end{tabular}


because of other neurological risk factors, leaving 44 exposed and 31 control workers for the analysis. For 12 retired workers and four with a disability pension the preretirement exposure state (exposed or control) was used. Exposed and control workers included in the second study were aged 51.9 (SD $7.5)$ and 51.9 (SD 6.5) years, respectively. Exposed workers had been employed for $26 \cdot 1$ (SD $7 \cdot 5$ ) years (minimum of 10 years at the time of the first study).

\section{EXPOSURE}

In the first study six homogeneous exposure categories had been identified with exposure levels assigned on the basis of personal air samples. Spot samples taken from 1948 onwards indicated that exposure had not changed during the years. The exposure of 10 workers in another factory before 1976 was estimated on the basis of limited data. The left column of table 1 shows exposures for the categories in the first study. From the duration and intensity of exposure the cumulative exposure $E_{c}$ was calculated in ppm-years. In using $E_{c}$ it is implicit that recent and former exposures contribute equally to present neural impairment. Slight impairment may recur, however, after cessation of exposure and may even recur during low exposure. For this reason we also allowed for a smaller contribution of past exposure to the actual impairment by weighting the cumulative exposure with half times of 10 and five years $\left(E_{10}\right.$ and $E_{5}$ respectively: for example, if a worker's exposure has always been $8 \mathrm{ppm}, \mathrm{E}_{5}$ counts the exposure at five years ago as $\frac{1}{2} \times 8=4 \mathrm{ppm}$, at 10 years ago as $\left(\frac{1}{2}\right)^{2} \times 8=$ 2 ppm, and so on).

The grouping of functions into exposure categories and the estimation of these categories' exposure levels have been carefully revised. The allegedly complete job circulation within categories sometimes seemed to be limited and three highly exposed transporters (until 1984) were identified. Additional personal air samples were available to estimate the category specific exposure levels. Table 1 summarises the consequences of these changes for the grouping of workers and the cate-

Table 2 Cumulative exposure (ppm-years) of exposed workers (arithmetic mean (SD)); unweighted and with half times of 10 and five years. The second and third column refer to exposed workers identified on the basis of the revised occupational histories.

\begin{tabular}{llll}
\hline $\begin{array}{l}\text { Exposure } \\
\text { weighting }\end{array}$ & $\begin{array}{l}\text { First study } \\
\text { original } \\
(n=45) \\
\text { half time }\end{array}$ & $\begin{array}{l}\text { First study } \\
\text { revised } \\
(n=47)\end{array}$ & $\begin{array}{l}\text { Second study } \\
(n=44)\end{array}$ \\
\hline Unweighted $\left(\mathrm{E}_{\mathrm{c}}\right)$ & $156(149)$ & $192(156)$ & $213(166)$ \\
Mean $(S D)$ & Mean $(S D)$ \\
5 years $\left(\mathrm{E}_{5}\right)$ & $70(47)$ & $84(50)$ & $81(46)$ \\
& $40(24)$ & $47(25)$ & $42(22)$ \\
\hline
\end{tabular}

gory specific exposure levels. The workers' occupational histories were reassessed by interviewing the workers and past and present key figures from the personnel and occupational health departments, and by an exhaustive record search. For two alleged controls past exposure was discovered. Table 2 shows cumulative exposures for both studies. The decrease in $E_{10}$ and $E_{5}$ between the first and the second study is a result of the weighting of the past high exposure of the transporters and workers from the other plant. Figure 1 shows the original and the revised cumulative exposure $\mathrm{E}_{\mathrm{c}}$ of the first study $(r=0.97$ without controls; $r \stackrel{c}{=} 0.95$ without the controls and the highly exposed subject).

\section{EXAMINATION OF NERVE FUNCTION}

The subjects were examined in warm rooms in the occupational health centre on the factory site. The investigator did not know the subjects' exposure state.

\section{Autonomic nerve function}

The applied methods were the same in both studies. The variability of the heart rhythm was measured during rest (resting arrhythmia, RA) as well as during maximal voluntary isometric contraction of the hand muscles (muscle heart reflex, MHR) and during maximal forced respiration (forced respiratory sinus arrhythmia, FRSA). Autonomic nerve impairment results in decreased responses.

\section{Neurophysiological examination}

Compared with the first study a number of technical improvements were implemented. Dantec Counterpoint electromyographs were used, applying 1.2 times supramaximal current stimuli (instead

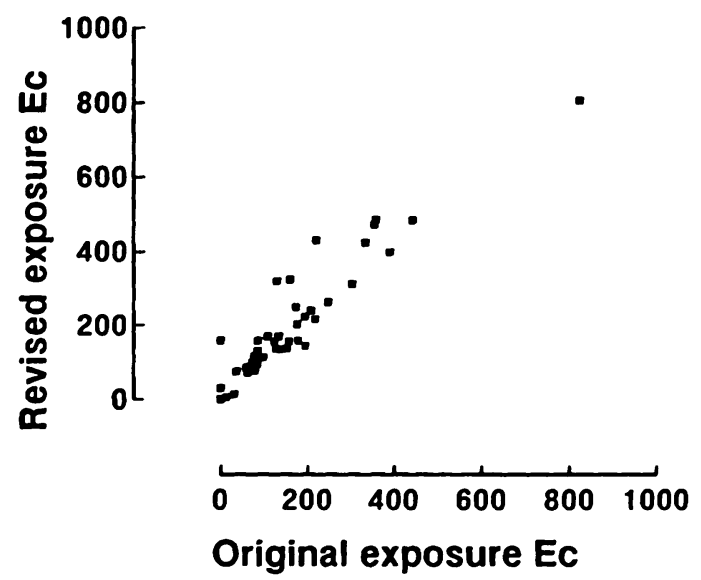

Figure 1 Relation between the original and revised unweighted cumulative exposure $E_{c}$ of the first study. 
of voltage). The arm and leg were prewarmed in hot water and controlled at $35^{\circ} \mathrm{C}$ by means of an infrared heater (instead of measuring the temperature and controlling in the analysis).

The standard motor nerve conduction velocity (MNCV), distal latency (DL), and response amplitudes (Mot Amp) ${ }^{8}$ were measured in the peroneal, median, and ulnar nerves. In the peroneal nerve the complete distribution of motor refractory periods (MRP) was measured according to Kimura ${ }^{19}$ and of motor conduction velocities according to Hopf (taking into account the individual MRP). ${ }^{10}$ For both methods the 80 th and 50 th percentiles of the acquired frequency distribution were used as indices reflecting the condition of the slower/average conducting and longer/average refractory fibres in the nerve $\left(\mathrm{MNCV}_{80}, \mathrm{MNCV}_{50}\right.$ and $\mathrm{MRP}_{80}$, $M R P_{50}$ respectively). In the first study the $\mathrm{MNCV}_{80}$ and $\mathrm{MRP}_{50}$ (then called $\mathrm{CVSF}_{\mathrm{RP}}$ and $\mathrm{MRP}$ ) had been determined.

The standard sensory nerve conduction velocity (SNCV) and response amplitudes (Sens Amp) ${ }^{8}$ were measured in the sural, median, and ulnar nerves (in the last two specifically for the hand (SNCVhand) and forearm sections (SNCVarm)). In the sural nerve the distribution of sensory refractory periods (SRP) was measured. Again, the 80th and 50th percentiles were used as indices $\left(\mathrm{SRP}_{80}\right.$ and $\mathrm{SRP}_{50}$ respectively); in the previous study the $\left(\mathrm{SRP}_{50}\right.$ (then called $\left.\mathrm{SRP}\right)$ was determined.

\section{Questionnaires}

After the examination the subjects, assisted by an investigator, completed a questionnaire about lifestyle (alcohol consumption), criteria for exclusion from the analyses, symptoms related to neuropathy, and occupational history within and outside the company.

\section{$Z$ scores}

Each test result contains information (signal) on nerve function and noise due to random measurement error. Combination of a number of related nerve functions may improve the signal to noise ratio; for this purpose we used $Z$ scores. A subject's $\mathrm{Z}$ score for a particluar test is $(\mathrm{x}-\mathrm{m}) / \mathrm{SD}$ where $\mathrm{x}$ is the subject's test result, $m$ and $S D$ are the complete group's average and standard deviation for that test. Thus the group mean and standard deviation of a test $Z$ score are 0 and 1 . A number of test $Z$ scores of related individual tests were combined in summary $\mathrm{Z}$ scores. The calculation was made in such a way that a negative sign of a $Z$ score is always in the pathological direction and that the complete group's mean and standard deviation were 0 and 1 . Such $Z$ scores were calculated for conduction of all motor and sensory nerves, for the autonomic nerves, for the refractory period indices (functional aggregation) and for the median, ulnar, peroneal, and sural nerve (anatomical aggregation).

\section{DATA ANALYSIS}

Neurophysiological data

For both studies the differences between the exposed $(n=44)$ and the control group $(n=31)$ were calculated with analysis of covariance (ANCOVA). The potential confounders age and life time alcohol comsumption were always included as covariables; for peripheral nerve indices the skin temperature (first study only) and body length were additionally included. Six workers were excluded from the ANCOVA analyses who had only been exposed as shift leaders or whose exposure had started in 1988. The effects of cumulative exposure were calculated with multiple linear regression analysis (MLR); the controls had a cumulative exposure of zero. The same covariables were used as in the ANCOVA. Non-normal distributed dependent variables were always $\log$ transformed; the residuals of all models were analysed and complied with the requirements. A $5 \%$ one sided significance level and a $90 \%$ two sided confidence interval were used; MLR analyses were performed with the weighted cumulative exposures $E_{10}$ and $E_{5}$ to obtain a tentative indication for the reversibility of the effects.

\section{Combined analysis}

For the determination of the final result of the two studies it is logical to combine the test results whenever possible. This is only sensible if these are replicate measurements of the same nerve function. To check this a correlation analysis was used. The neurophysiological indices of the first study were corrected to a temperature of $35^{\circ} \mathrm{C}$. In the combined analysis the mentioned covariables were included in the models.

\section{Questionnaire data}

The prevalence odds ratio of symptoms was calculated; exact significance and interval estimation was applied because of the small numbers.

\section{Results \\ SEPARATE ANALYSIS OF THE STUDIES \\ Reanalysis of the first study}

The results of the reanalysis differ from those of the original analysis due to revision of the exposure data. In the reanalysis a group difference (ANCOVA, not presented) was found in MNCV $(-1.1 \mathrm{~m} / \mathrm{s})$ and, as in the original analysis, in $\mathrm{MNCV}_{80}(-1.3 \mathrm{~m} / \mathrm{s})$. For the autonomic nerve indices MHR $(-5 \cdot 1$ beats $/ \mathrm{min}), \quad$ FRSA $(-3.9$ beats $/ \mathrm{min})$, and $Z_{\text {aut }}(-0.6)$ group differences were found that were stronger than in the original analysis (not presented). Table 3 shows the 
Table 3 Separate analysis of the studies

\begin{tabular}{|c|c|c|c|c|c|c|c|c|}
\hline \multirow[b]{3}{*}{ Parameter units } & & & \multicolumn{4}{|c|}{ First study } & \multicolumn{2}{|c|}{ Second study } \\
\hline & \multirow{2}{*}{\multicolumn{2}{|c|}{$\begin{array}{l}\text { Mean value } \\
(S D) \text { of controls }\end{array}$}} & \multicolumn{2}{|l|}{ Original } & \multicolumn{2}{|c|}{ Reanalysis } & \multirow[b]{2}{*}{ Effect } & \multirow[b]{2}{*}{$p$ Value } \\
\hline & & & Effect & $p$ Value & Effect & p Value & & \\
\hline $\begin{array}{l}\text { Peroneal nerve: } \\
\text { MNCV }(\mathrm{m} / \mathrm{s}) \\
\operatorname{Mot} A \mathrm{mp}(\mathrm{mV}) \\
\mathrm{MNCV}_{80}(\mathrm{~m} / \mathrm{s}) \\
\mathrm{MRP}_{50}(\mathrm{~ms})\end{array}$ & $\begin{array}{c}48 \cdot 1 \\
6 \cdot 9 \\
41 \cdot 5 \\
1.59\end{array}$ & $\begin{array}{l}(3 \cdot 8) \\
(2 \cdot 5) \\
(3 \cdot 2) \\
(0 \cdot 4)\end{array}$ & $\begin{array}{l}-0.39 \\
-0.05 \\
-0.62 \\
+0.05\end{array}$ & $\begin{array}{l}0.08 \\
0.41 \\
0.02^{\star} \\
0.05^{\star}\end{array}$ & $\begin{array}{l}-0.33 \\
+0.03 \\
-0.36 \\
+0.04\end{array}$ & $\begin{array}{l}0.07 \\
0.44 \\
0.06 \\
0 \cdot 10\end{array}$ & $\begin{array}{l}-0.47 \\
+0.24 \\
-0.47 \\
-0.00\end{array}$ & $\begin{array}{l}0 \cdot 02^{\star} \\
0 \cdot 12 \\
0 \cdot 02^{\star} \\
0 \cdot 46\end{array}$ \\
\hline $\begin{array}{l}\text { Sural nerve: } \\
\text { SNCV }(\mathrm{m} / \mathrm{s}) \\
\text { Sens Amp }(\mu \mathrm{V}) \\
\text { SRP }_{50}(\mathrm{~ms})\end{array}$ & $\begin{array}{c}52 \cdot 5 \\
9 \cdot 8 \\
1 \cdot 29\end{array}$ & $\begin{array}{l}(4 \cdot 9) \\
(4 \cdot 3) \\
(0 \cdot 5)\end{array}$ & $\begin{array}{l}+0.05 \\
-0.03 \\
-0.01\end{array}$ & $\begin{array}{l}0.45 \\
0.47 \\
0.40\end{array}$ & $\begin{array}{l}-0.02 \\
-0.11 \\
-0.01\end{array}$ & $\begin{array}{l}0.47 \\
0.38 \\
0.38\end{array}$ & $\begin{array}{l}-0.29 \\
-0.04 \\
+0.03\end{array}$ & $\begin{array}{l}0.15 \\
0.45 \\
0.05\end{array}$ \\
\hline $\begin{array}{l}\text { Autonomic nerve function: } \\
\text { MHR (beats/min) } \\
\text { FRSA (beats } / \mathrm{min} \text { ) } \\
\text { RA (beats } / \mathrm{min} \text { ) } \\
\mathrm{Z}_{\text {aut }}\end{array}$ & $\begin{array}{r}19 \cdot 5 \\
22 \cdot 2 \\
2 \cdot 5 \\
0 \cdot 3\end{array}$ & $\begin{array}{l}(9 \cdot 2) \\
(8 \cdot 4) \\
(0 \cdot 9) \\
(1 \cdot 0)\end{array}$ & $\begin{array}{l}-0.92 \\
-0.75 \\
-0.00 \\
-0.12\end{array}$ & $\begin{array}{l}0 \cdot 11 \\
0 \cdot 17 \\
0 \cdot 48 \\
0 \cdot 08\end{array}$ & $\begin{array}{l}-1 \cdot 31 \\
-0.73 \\
+0.01 \\
-0.10\end{array}$ & $\begin{array}{l}0.03^{\star} \\
0.15 \\
0.45 \\
0.09\end{array}$ & $\begin{array}{l}-0.42 \\
-0.51 \\
+0.04 \\
-0.03\end{array}$ & $\begin{array}{l}0 \cdot 26 \\
0 \cdot 20 \\
0 \cdot 29 \\
0 \cdot 35\end{array}$ \\
\hline
\end{tabular}

Mean (SD) of the control group (raw data first study) for indices that have been measured twice. Calculated effect of $100 \mathrm{ppm}-$ years unweighted cumulative exposure $\mathrm{E}_{c}(\mathrm{MLR})$ for the original analysis and reanalysis of the first study, and for the second study with $p$ values; ${ }^{\star} \mathrm{p}<0.05$.

consequences of the change in $\mathrm{E}_{\mathrm{c}}$. The formerly significant associations of peroneal nerve $\mathrm{MNCV}_{80}$ and $\mathrm{MRP}_{50}$ with $\mathrm{E}_{\mathrm{c}}$ were not confirmed; an additional association was found for $\mathrm{E}_{\mathrm{c}}$ with $\mathrm{MHR}$.

\section{Second study}

In the MLR (table 3) and ANCOVA analyses decreases were found in $\mathrm{MNCV}, \mathrm{MNCV}_{50}$, and $\mathrm{MNCV}_{80}$. The major alteration compared with the first study was detection of impaired nerve functions in the sural nerve and increased evidence for slight polyneuropathy based on impairments in the additionally examined arm nerves (see summary analysis). The $Z$ scores show the general localisation of the nerve impairment (fig 2). In general sensory nerves seemed to be more impaired than motor nerves.

The prevalence of single reported symptoms that indicated periperal neuropathy was $6-20 \%$; odds ratios of about 1 were found with wide confidence intervals. This result serves as an imprecise indication that the exposed workers' prevalence of symptoms had not increased.

\section{SUMMARY ANALYSIS}

Figure 3 shows the correlation coefficients between the results of the two studies. The results for autonomic nerves of the two studies were treated as replicate measurements because of identical examination methods. The low correlation for the RA probably indicates a poor reproducibility. For sural nerves the methodology in the second study had improved to such an extent that these results were logically favoured. The improvement was not so pronounced for peroneal nerve indices, so these were treated as replicate measurements because the correlation between results of both studies was satisfactory (fig 3). Thus combined analyses were performed with all peroneal nerve and autonomic nerve indices.

Table 4 presents summary results of the two studies. There is evidence for impairment of a number of peripheral nerve indices, particularly of conduction velocities in the nerves of arms and legs (peroneal nerve $\mathrm{MNCV}-0.9 \mathrm{~m} / \mathrm{s}, \mathrm{MNCV}_{80}$ $-0.1 \mathrm{~m} / \mathrm{s}$ ). In arm nerves sensory fibres were particularly affected. Most of the observed differences in peripheral nerves were exposure related. The increase in sural nerve SRP $(+0.2 \mathrm{~ms})$ was pronounced in this study. No decrease was found in

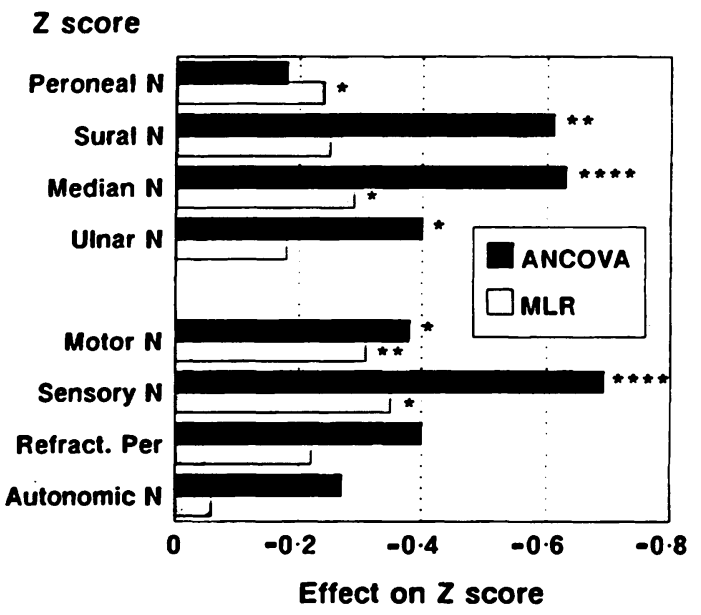

Figure 2 Effects on the $Z$-scores in the second study. A negative $Z$-score indicates an effect in the pathological direction. ${ }^{*} p<0.05 ;{ }^{*} p<0.01 ;{ }^{*}{ }^{*} p<0.005$; $\star \star \star \star x p 0.001$. 


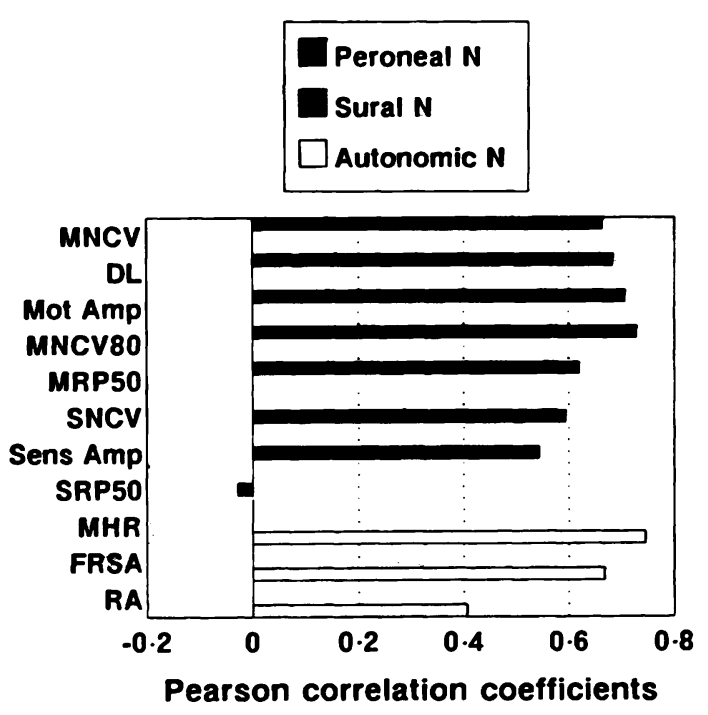

Figure 3 Pearson correlation coefficients between the results of the first and second study.

motor or sensory compound action potential amplitudes. Weighted cumulative exposures $\mathrm{E}_{10}$ and $\mathrm{E}_{5}$ correlated less well than unweighted cumulative exposure with peripheral nerve indices. For autonomic nerve function a decrease was found in MHR ( -4.7 beats/min, $-26 \%)$ and FRSA ( -3.2 beats/min, $-16 \%$ ) by ANCOVA and with the weighted cumulative exposures $E_{10}$ and $E_{5}$ (not presented). No relation with unweighted cumulative exposure was found, and no decrease in the RA.

\section{Discussion \\ EXPOSURE}

In the second study we were able to establish exposure to $\mathrm{CS}_{2}$ and occupational histories more precisely; particularly the workers' occupational histories. A major uncertainty remaining is the fragmentary character of the data about past exposure of 10 workers in another factory; a plausible $20 \%$ error in this exposure would substantially alter the $E_{c}$ as this exposure period was responsible for about $60 \%$ of cumulative exposure. A second uncertainty is that large interindividual differences may exist within exposure categories.

The nature of the applied exposure parameter determines which specific exposure-effect relation is being evaluated; often only the exposure state is used, implicitly assuming equal exposure for all exposed workers. We chose cumulative exposure as there are strong indications that the duration

Table 4 Summary results: effects on the averaged values of the two studies; effects in nerves and on parameters indicated with $f$ are from the second study

\begin{tabular}{|c|c|c|c|c|}
\hline \multirow[b]{2}{*}{ Parameter units } & \multicolumn{2}{|c|}{ Uncorrected values } & \multirow{2}{*}{$\begin{array}{l}\text { Difference exposed } \\
\text { minus controls } \\
(90 \% \mathrm{CI})\end{array}$} & \multirow{2}{*}{$\begin{array}{l}\text { Effect of average } \\
\text { cumulative exposure } \\
(90 \% \text { CI })\end{array}$} \\
\hline & $\begin{array}{l}\text { Controls } \\
\text { Mean SD }\end{array}$ & $\begin{array}{l}\text { Exposed } \\
\text { Mean SD }\end{array}$ & & \\
\hline 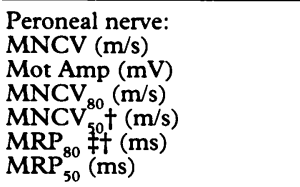 & $\begin{aligned} 47.9(3.7) \\
6 \cdot 4(2 \cdot 4) \\
41 \cdot 7(3.2) \\
45 \cdot 4(3.8) \\
1.70(1 \cdot 2) \\
1.50(0.3)\end{aligned}$ & $\begin{aligned} & 47 \cdot 0(4 \cdot 0) \\
& 7 \cdot 4(2 \cdot 5) \\
& 40 \cdot 4(4 \cdot 0) \\
& 44 \cdot 1(4 \cdot 6) \\
& 1 \cdot 63(1 \cdot 2) \\
& 1 \cdot 43(0 \cdot 3)\end{aligned}$ & $\begin{array}{l}-1.2(-2.3 \text { to }-0.1)^{\star} \\
+0.8(-0.2 \text { to }+1.7)^{\star \star} \\
-1.6(-2.7 \text { to }-0.5)^{\star \star} \\
-1.5(-2.8 \text { to }-0.2)^{\star} \\
-0.1(-0.2 \text { to }+0.0) \\
-0.0(-0.2 \text { to }+0.1)\end{array}$ & $\begin{array}{l}-0.9(-1.6 \text { to }-0.1)^{\star} \\
+0.3(-0.4 \text { to }+0.9) \\
-1.0(-1.7 \text { to }-0.3)^{\star} \\
-0.9(-1.7 \text { to }-0.0)^{\star} \\
-0.0(-0.1 \text { to }+0.1) \\
+0.0(-0.0 \text { to }+0.1)\end{array}$ \\
\hline $\begin{array}{l}\text { Sural nerve: } † \\
\text { SNCV (m/s) } \\
\text { Sens Amp }(\mu \mathrm{V}) \\
\text { SRP }_{80} \ddagger(\mathrm{ms}) \\
\text { SRP }_{50} \neq(\mathrm{ms})\end{array}$ & $\begin{array}{r}50 \cdot 3(3 \cdot 5) \\
11 \cdot 2(5 \cdot 5) \\
1.47(1 \cdot 2) \\
1 \cdot 10(1 \cdot 2)\end{array}$ & $\begin{array}{cc}49 \cdot 2(2 \cdot 9) \\
10 \cdot 6(6 \cdot 1) \\
1 \cdot 78(1 \cdot 2) \\
1 \cdot 25(1 \cdot 2)\end{array}$ & $\begin{array}{l}-1.3(-2.5 \text { to }-0.1)^{\star} \\
-1.0(-1.9 \text { to }-0.1)^{\star} \\
+0.4(+0.2 \text { to }+0.5)^{\star \star \star \star} \\
+0.2(+0.1 \text { to }+0.3)^{\star \star \star}\end{array}$ & $\begin{array}{l}-0.5(-1.3 \text { to }+0.3) \\
-0.2(-1.3 \text { to }+1 \cdot 1) \\
+0.2(+0.1 \text { to }+0.3)^{\star \star \star} \\
+0.1(-0.0 \text { to }+0.1)\end{array}$ \\
\hline $\begin{array}{l}\text { Median nerve:† } \\
\text { MNCV }(\mathrm{m} / \mathrm{s}) \\
\text { SNCVhand }(\mathrm{m} / \mathrm{s}) \\
\text { SNCVarm }(\mathrm{m} / \mathrm{s})\end{array}$ & $\begin{array}{ll}56 \cdot 8 & (3.9) \\
55.8 & (3.9) \\
60 \cdot 8 & (2 \cdot 7)\end{array}$ & $\begin{array}{ll}55 \cdot 2 & (3 \cdot 8) \\
53 \cdot 5 & (4 \cdot 7) \\
58 \cdot 6 & (4 \cdot 4)\end{array}$ & $\begin{array}{l}-1.5(-2.9 \text { to }-0.0)^{\star} \\
-2.9(-4.5 \text { to }-1.2)^{\star \star \star} \\
-1.8(-3.2 \text { to }-0.3)^{\star}\end{array}$ & $\begin{array}{l}-0.5(-1.6 \text { to }+0.5) \\
-2 \cdot 1(-3.2 \text { to }-1 \cdot 0)^{\star \star \star} \\
-1 \cdot 1(-2 \cdot 1 \text { to }-0.1)^{\star}\end{array}$ \\
\hline $\begin{array}{l}\text { Ulnar nerve: } \dagger \\
\text { MNCV }(\mathrm{m} / \mathrm{s}) \\
\text { SNCVhand }(\mathrm{m} / \mathrm{s}) \\
\text { SNCVarm }(\mathrm{m} / \mathrm{s})\end{array}$ & $\begin{array}{ll}58 \cdot 4 & (4 \cdot 2) \\
53 \cdot 2 & (4 \cdot 1) \\
63 \cdot 8 & (4 \cdot 3)\end{array}$ & $\begin{array}{ll}57 \cdot 8 & (4 \cdot 3) \\
52 \cdot 2 & (4 \cdot 2) \\
60 \cdot 9 & (4 \cdot 5)\end{array}$ & $\begin{array}{l}-0.4(-2 \cdot 1 \text { to }+1 \cdot 3) \\
-1 \cdot 1(-2 \cdot 8 \text { to }+0 \cdot 5) \\
-2 \cdot 8(-4 \cdot 6 \text { to }-1 \cdot 1)^{\star \star}\end{array}$ & $\begin{array}{l}-0.0(-1.2 \text { to }+1.2) \\
-1.3(-2.4 \text { to }-0.2)^{\star} \\
-1.6(-3.0 \text { to }-0.2)^{\star}\end{array}$ \\
\hline $\begin{array}{l}\text { Autonomic nerve function: } \\
\text { MHR (beats/min) } \\
\text { FRSA (beats/min) } \\
\text { RA (beats/min) }\end{array}$ & $\begin{aligned} 17 \cdot 9 & (8 \cdot 0) \\
19 \cdot 5 & (7 \cdot 2) \\
1 \cdot 7 & (0 \cdot 7)\end{aligned}$ & $\begin{array}{rr}12 \cdot 9 & (6 \cdot 3) \\
17 \cdot 0 & (7 \cdot 6) \\
2 \cdot 0 & (0 \cdot 9)\end{array}$ & $\begin{array}{l}-4.7(-7.3 \text { to }-1.9)^{\star \star} \\
-3.2(-5.3 \text { to }-0.4)^{\star} \\
+0.2(-0.2 \text { to }+0.5)\end{array}$ & $\begin{array}{l}-3.7(-7.8 \text { to }+0.5) \\
-2.3(-6.5 \text { to }+1.9) \\
+0.1(-0.2 \text { to }+0.3)\end{array}$ \\
\hline
\end{tabular}

${ }^{\star} \mathrm{p}<0.05 ;{ }^{\star \star} \mathrm{p}<0.01 ;{ }^{\star \star \star} \mathrm{p}<0.005 ;{ }^{\star \star \star \star \star} \mathrm{p}<0.001$.

‡Geometric mean and GSD for log transformed parameters; difference exposed minus control group (ANCOVA) and calculated effect of the average cumulative exposure from the MLR (207 ppm - years for parameters from the combined study or $213 \mathrm{ppm}-$ years for the parameters from the second study), both with $90 \%$ confidence intervals ( $90 \%$ CIs). 
of exposure should be taken into account. ${ }^{234}$ Although $\mathrm{E}_{\mathrm{c}}$ is probably a better measure of exposure we still do not know its influence on the true exposure effect relation. Also, random error in $\mathrm{E}_{\mathrm{c}}$ will result in underestimation of the regression coefficient and reduction of the sensitivity of the analysis (attenuation).

Despite the elaborate information on occupational histories the best estimate of cumulative exposure only incompletely reflects a worker's true exposure. The exposure data in this factory are elaborate compared with similar $\mathrm{CS}_{2}$ studies. The mentioned limitations are unfortunately inherent to this type of study.

\section{COMBINED ANALYSIS}

The comparability of data on nerve function from the two studies is important when results of the studies are combined. There are several sources of potential bias. The improved EMG apparatus in the second study resulted in less drop out due to missing or uninterpretable results, in particular for sural nerve indices. Refractory periods may not be completely comparable because 1.2 times maximal stimulation in current and voltage are not equal. The temperature correction of neurophysiological data from the first study $\left(0-4^{\circ} \mathrm{C}, 1-2 \mathrm{~m} / \mathrm{s}\right.$ per $\left.{ }^{\circ} \mathrm{C}\right)$, can also be a source of difference. The examination of autonomic nerve function was unchanged. Due to implementation of improved examination methods data on nerve function from the second study were logically favoured in cases of conflicting results, as happened for the sural nerve.

Analyses with averaged data were performed with those parameters for which results from the two studies were considered to be replications, thereby reducing random error, which consists of biological intraindividual variation and measurement error. Final conclusions are drawn from this analysis whenever possible. We did not perform longitudinal analyses with the difference of the results between the studies because the expected magnitude of effect of four years further exposure to $\mathrm{CS}_{2}$ was small compared with random and systematic errors.

EFFECTS

The change in the number of statistically significant effects related to revised exposure data is remarkable considering the small changes and the high correlation between the original and revised cumulative exposure. Our results indicate that the outcome of epidemiological toxicological studies aimed at measuring small effects may be sensitive to the nature and accuracy of the exposure parameter applied in the analysis.

It is reassuring that the first study and the second study agreed as far as effects are concerned, espe- cially when the small magnitude of the effects is taken into account. This is an indication for the actual existence of these effects. For peripheral nerves the extended observations indicate a decrease in conduction velocity of fast and slow motor nerve fibres of the peroneal nerve (MNCV, $\mathrm{MNCV}_{50}$, and $\mathrm{MNCV}_{80}$ ). This is more serious than the first study (and some other publications) indicated in which only slow fibres were affected. Furthermore, sensory conduction velocities were reduced and the sensory refractory period of the sural nerve increased. The localisation of the effects resembles the distribution of signs and symptoms in polyneuropathy. The relation with cumulative exposure supports the causality of the exposure. Because weighted cumulative exposures correlated less well with the peripheral nerve indices, there is no indication that the effects on peripheral nerves are reversible. For the autonomic nerve parameters the association with recent and past exposure was different compared with the peripheral nerves. Here, the weighted cumulative exposures $E_{10}$ and $E_{5}$ correlated better with the nerve parameters, indicating the relative importance of recent exposure; an explanation for this phenomenon may be reversibility of these specific effects.

\section{HEALTH IMPLICATIONS}

In the case of an axonal type of neuropathy the slowing of conduction velocity is a secondary phenomenon, which may be slight even in a serious stage. The small decrease in conduction velocities in the absence of symptoms of neuropathy and decreased response amplitudes suggest a mild presymptomatic nerve impairment. It is difficult to indicate the seriousness of the effects on the autonomic nervous system due to lack of reference material and findings in patients with autonomic neuropathy. Finally the effects are probably underestimated because of the inevitable deficits of the model and attenuation. The analyses with weighted exposures suggest that at least a part of the effects are irreversible. We consider these effects undesirable as they may reduce the workers' reserve capacity to cope with other noxious influences, and in view of the possible additivity of the effects of exposure and ageing.

\section{Conclusion}

The reinvestigation has reinforced in two ways the conclusion of the first study that low exposure to $\mathrm{CS}_{2}$ affects the peripheral and autonomic nervous systems. Firstly, the effects of the two separate studies corresponded well after improving the estimation of exposure, despite the change in examination methods. Secondly, effects related to exposure were shown to exist in the combined analysis. 
We are indebted to Chris Braun, Hans van der Stolpe, and Arnold Giesen of the company's occupational health service for their general support and help with the estimation of past exposure. This study was financially supported by Akzo Fibers BV.

1 Ruijten MWMM, Sallé HJA, Verberk MM, Muijser H. Special nerve functions and colour discrimination in workers with long term low level exposure to carbon disulphide. $\mathrm{Br} \mathcal{F}$ Ind Med 1990;47:589-95.

2 Seppäläinen AM, Haltia M. Carbon Disulfide. In: Spencer PS and Schaumburg $\mathrm{HH}$, eds. Experimental and clinical neurotoxicology. Baltimore: Wiliams and Wilkins, 1980:356-73.

3 Beauchamp RO, Bus JS, Popp JA, et al. A critical review of the literature on carbon disulfide toxicity. CRC Crit Rev Toxicol 1983;11:169-278.

4 Johnson BL, ed. Prevention of neurotoxic illness in working populations. Chichester: John Wiley and Sons, 1987.
5 Corsi G, Maestrelli O, Picotti G, et al. Chronic peripheral neuropathy in workers with previous exposure to carbon disulphide. Br F Ind Med 1980;40;209-11.

6 Johnson BL, Boyd J, Burg RR, et al. Effects on the peripheral nervous system of workers' exposure to carbon disulfide. Neurotoxicology 1983;4:53-66.

7 Aaserud O, Gjerstad L, Nakstad P, et al. Neurological examination, computerised tomography, cerebral blood flow and neuropsychological examination in workers with long-term exposure to carbon disulfide. Toxicology 1988;49:277-82.

8 Kimura J. Electrodiagnosis in diseases of nerve and muscle: principles and practice. 2nd edition. Philadelphia, FA Davis comp, 1989.

9 Faisst S, Meyer M. A non-invasive computerized measurement of motor neurone refractory period and subnormal conduction in man. Electroencephalogr Clin Neurophysiol 1981;51:548-58.

10 Seppäläinen AM, Hernberg S. Sensitive technique for detecting subclinical lead neuropathy. $\mathrm{Br} \mathcal{F}$ Ind $M e d$ 1972;28: 443-9.

Accepted 6 July 1992

\section{Vancouver style}

All manuscripts submitted to the $B r \mathcal{F}$ Ind $M e d$ should conform to the uniform requirements for manuscripts submitted to biomedcical journals (known as the Vancouver style.)

The $\mathrm{Br} \mathcal{F}$ Ind $\mathrm{Med}$, together with many other international biomedical journals, has agreed to accept articles prepared in accordance with the Vancouver style. The style (described in full in $\mathrm{Br}$ F Ind Med, 24 February 1979, p 532) is intended to standardise requirements for authors.

References should be numbered consecutively in the order in which they are first mentioned in the test by Arabic numerals above the line on each occasion the reference is cited (Manson ${ }^{1}$ confirmed other reports ${ }^{2-5} \ldots$. .). In future references to papers submitted to the $\mathrm{Br} \mathcal{F}$ Ind $\mathrm{Med}$ should include: the names of all authors if there are six or less or, if there are more, the first three followed by et al; the title of journal articles or book chapters; the titles of journals abbreviated according to the style of Index Medicus; and the first and final page numbers of the article or chapter.

Examples of common forms of references are:

1 International Steering Committee of Medical Editors, Uniform requirements for manuscripts submitted to biomedical journals. Br f Ind Med 1979;1:532-5.

2 Soter NA, Wasserman SI, Austen KF. Cold urticaria: release into the circulation of histamine and eosino-phil chemotactic factor of anaphylaxis during cold challenge. N Engl f Med 1976;294:687-90.

3 Weinstein L, Swartz MN. Pathogenic properties of invading micro-organisms. In: Soderman WA Jr, Soderman WA, eds. Pathologic physiology, mechanisms of disease. Philadelphia: W B Saunders, 1974:457-72. 